\title{
Comunicação
}

[Communication]

\section{Efeito do transporte de péletes sobre sua qualidade}

\author{
[Effect of pellets transport on its quality]
P.C. Cardeal, J.S.R. Rocha, H.C. Ferreira, C.H. Santos, M.A. Pompeu, C.E. Cunha, N.C. Baião, L.J.C. Lara \\ Escola de Veterinária - Universidade Federal de Minas Gerais - UFMG - Belo Horizonte, MG
}

A peletização é um processo mecânico, que tem como objetivo agregar as partículas dos alimentos por meio de compressão sob altas temperaturas $\left(80\right.$ a $\left.90^{\circ} \mathrm{C}\right)$ e vapor (Nir, 1998), a fim de obter péletes com grau de durabilidade suficiente para suportar as condições de transporte e manuseio.

Melhor desempenho em frangos de corte alimentados com rações peletizadas, como aumento do ganho de peso e melhora na conversão alimentar, foi encontrado por Meiners et al. (2001) e López e Baião (2004). SkinnerNoble et al. (2005) relacionaram o desempenho superior das aves com o menor tempo gasto na apreensão dos péletes da ração, aumentando, assim, o tempo de descanso, o que resulta em maior quantidade de energia disponível para o ganho de peso dos frangos. Os efeitos benéficos da peletização estão relacionados com melhorias na digestibilidade de nutrientes devido à gelatinização do amido, melhor digestibilidade das fontes lipídicas e desnaturação de proteínas (Dozier, 2001; López e Baião, 2004). A utilização de rações com percentual de péletes íntegros acima de $40 \%$ proporciona maior ganho de peso e melhor conversão alimentar, podendo haver diminuição dos benefícios da peletização quando as aves são alimentadas com péletes de má qualidade (Mckinney e Teeter, 2004).

Durante a produção de ração peletizada, o maior desafio das fábricas é produzir péletes de boa qualidade. A eficácia desse processo é comprovada pela qualidade dos péletes, que é definida como a resistência à quebra, desde o momento em que são produzidos na fábrica de ração até a sua distribuição nos comedouros das granjas (Thomas e Van der Poel, 1996). Existem dois meios de avaliar essa qualidade: o índice de durabilidade do pélete (PDI) e o método Embrapa de avaliação de peletização (MEP). Em ambos os métodos é possível saber que porcentagem de ração não gerou finos após passar por uma simulação do transporte da ração da fábrica à granja.

Para que a qualidade alcançada na produção dos péletes dentro da fábrica de ração seja mantida durante seu transporte até seu destino, é necessário que estes sejam transportados de forma adequada. O caminhão transportador de ração é considerado um ponto crítico para manter a qualidade da ração produzida, pois sua rosca transportadora pode, durante a descarga, quebrar os péletes (Klein, 1999). De acordo com Sheideler (1995), percentual de finos durante o transporte pode aumentar de $33 \%$ para $59 \%$. Esse valor pode chegar até $72 \%$ no comedouro dos frangos.

O objetivo do presente trabalho foi avaliar a qualidade do pélete, desde a saída da peletizadora até o fim da linha de comedouros de frangos de corte, empregando dois métodos de análise de qualidade: índice de durabilidade do pélete (PDI) e o método Embrapa de avaliação de peletização (MEP). Ainda, avaliou-se o efeito dos métodos de descarga da ração na granja sobre a qualidade física do pélete, utilizando, como método de análise, o MEP.

O experimento foi realizado na integração de frangos de corte da empresa Rivelli Alimentos, em Barbacena/MG, e foi dividido em duas fases experimentais. 
$\mathrm{Na}$ fase I, foram coletadas amostras de rações peletizadas da fase de crescimento, em seis pontos diferentes, desde a saída da peletizadora até o final da linha de comedouros, sendo cada ponto considerado um tratamento. Os tratamentos foram definidos pelo ponto de coleta de ração:

Tratamento A - na saída da peletizadora;

Tratamento B - dentro do caminhão após a sua carga;

Tratamento C - descarga do caminhão no silo da granja;

Tratamento D - caçamba de distribuição dentro do galpão;

Tratamento E - comedouro no meio da linha de comedouros;

Tratamento F - último comedouro da linha de comedouros.

Cada uma das sete amostras de ração foi dividida em duas alíquotas, sendo uma alíquota submetida ao teste de qualidade PDI e a outra submetida ao teste de qualidade MEP. Para determinação do MEP, foram pesados $300 \mathrm{~g}$ de ração de cada amostra, e esta foi peneirada em aparelho vibratório com peneira de abertura de $4 \mathrm{~mm}$ (Tyler 5) por 30 segundos. Após o processo, a amostra foi pesada novamente, e obtido o MEP pelo percentual sobre $300 \mathrm{~g}$, que não gerou finos (Schmidt et al., 2004). Para determinação do PDI, as amostras de ração foram peneiradas em peneira Tyler $8(2,36 \mathrm{~mm})$ por dois minutos. Foram pesados $500 \mathrm{~g}$ de ração peneirada e colocados em durabilímetro por 10 minutos, numa rotação de 50 a 55rpm. Após esse tempo, a amostra foi novamente peneirada em peneira Tyler 8 por dois minutos e pesada. O PDI é dado pelo percentual sobre $500 \mathrm{~g}$ que não gerou finos.

O delineamento foi em blocos ao acaso, composto por seis tratamentos (pontos de coleta) e sete repetições (rações que constituíram os sete blocos). Os dados foram submetidos à análise de variância, e as médias foram comparadas pelo teste SNK para o MEP, devido ao coeficiente de variação maior que $15 \%$, e pelo teste Tukey para o PDI, em razão de o coeficiente de variação ter sido inferior a 15\% (Sampaio, 2007).

Na fase II, a qualidade dos péletes foi avaliada durante a descarga de ração na granja. Foram coletadas amostras de ração logo após o carregamento de ração e durante a descarga na granja, de duas formas, compondo os seguintes tratamentos:

Tratamento Controle: coleta da ração no caminhão, logo após seu carregamento;

Tratamento A: coleta da ração durante a descarga com abertura menor da caixa do caminhão (apropriada para ração peletizada);

Tratamento B: coleta da ração durante a descarga com abertura maior da caixa do caminhão (apropriada para ração farelada).

Cada amostra de ração foi avaliada pelo MEP. A metodologia para obtenção do MEP foi a mesma realizada anteriormente. $\mathrm{O}$ delineamento foi em blocos ao acaso, composto por três tratamentos, sendo dois métodos de descarga e um grupo controle, e 12 repetições (rações que constituíram os 12 blocos). Os dados foram submetidos à análise de variância, e as médias foram comparadas pelo teste de Dunnet para comparação das descargas (A e B) com o grupo controle. Para comparação entre os dois métodos de descarga, foram utilizados 12 pares de rações que passaram pelos dois tratamentos, e a comparação das médias foi realizada pelo teste T-pareado (Sampaio, 2007).

A Tab. 1 apresenta os resultados de MEP e PDI para os tratamentos utilizados e a correlação de Pearson (r) entre as metodologias de avaliação da qualidade do pélete, da fase I.

Para os valores de MEP, a porcentagem de péletes íntegros é igual na saída da peletizadora e no caminhão $(\mathrm{P}>0,05)$. Porém, o valor do MEP se reduz significativamente no trajeto do caminhão até a descarga no silo (queda de aproximadamente $18 \%$ ) e mantém-se o mesmo até o final da linha de comedouros. Esse resultado evidenciou um possível problema na descarga do caminhão no silo da granja. Já o valor de PDI foi menor no primeiro ponto de coleta $(\mathrm{P} \leq 0,05)$ quando comparado aos demais pontos $(\mathrm{P}>0,05)$ entre si. Uma possível explicação para o menor valor de PDI no primeiro ponto é que os péletes não passaram por condições adversas que pudessem comprometer a sua qualidade, diferentemente do que aconteceu nos demais pontos. Após sair da fábrica, o pélete passa por situações que contribuem para sua quebra. Como o PDI é 
calculado com base em $500 \mathrm{~g}$ de péletes íntegros, ou seja, peneirados os péletes que permaneceram íntegros durante o transporte, após o teste estes são de qualidade e dureza superiores, o que é confirmado pelos resultados de PDI encontrados nos tratamento B, C, D, E e F.

Tabela 1. Médias do método Embrapa de avaliação de peletização (MEP) e do índice de durabilidade do pélete (PDI) em função dos pontos de coleta das rações e correlação de Pearson (r) entre as metodologias de avaliação da qualidade do pélete

\begin{tabular}{lccc}
\hline \multicolumn{1}{c}{ Pontos de coleta } & MEP $(\%)^{\mathrm{a}}$ & ${\text { PDI }(\%)^{\mathrm{b}}}^{\mathrm{b}}$ & $\mathrm{r}$ entre MEP e PDI $^{\mathrm{c}}$ \\
\hline A - Saída da peletizadora & $70,3 \mathrm{~A}$ & $79,0 \mathrm{~B}$ & 0,75 \\
B - Caminhão (após a carga) & $72,3 \mathrm{~A}$ & $85,3 \mathrm{~A}$ & 0,96 \\
C - Descarga no silo da granja & $57,7 \mathrm{~B}$ & $86,8 \mathrm{~A}$ & 0,91 \\
D - Caçamba & $57,9 \mathrm{~B}$ & $86,7 \mathrm{~A}$ & - \\
E - Meio da linha & $53,8 \mathrm{~B}$ & $84,4 \mathrm{~A}$ & 0,71 \\
F - Fim da linha & $46,3 \mathrm{~B}$ & $86,2 \mathrm{~A}$ & - \\
\hline CV $(\%)$ & 16,7 & 2,9 & \\
\hline
\end{tabular}

Médias seguidas de letras distintas na coluna diferem entre si pelos testes $\mathrm{SNK}^{\mathrm{a}}$ e de Tukey ${ }^{\mathrm{b}}(\mathrm{P} \leq 0,05){ }^{\mathrm{c}}$ valores de $\mathrm{r}$ significativos a $\mathrm{P} \leq 0,05$.

Houve correlação alta e positiva entre os métodos MEP e PDI em quatro dos seis pontos de coleta avaliados. Entretanto, o valor do PDI não mostra a real condição da relação entre péletes íntegros e finos da ração oferecida aos animais na granja, como pode ser demonstrado por meio do MEP. Além disso, o MEP permitiu determinar a descarga no silo como o ponto principal de influência sobre a qualidade do pélete, enquanto o mesmo fato não pôde ser observado pelo PDI. O PDI é um bom método de avaliação da resistência do pélete na fábrica, pois existe alta correlação com o MEP, que se mostrou mais adequado para avaliar a condição do pélete no campo. Uma alternativa para melhorar o processo seria a utilização do PDI sem peneirar a amostra, ou seja, uma união dos dois métodos estudados.

A Tab. 2 apresenta os resultados de MEP para os dois métodos de descarga da ração no silo da granja e para a ração ainda no caminhão logo após seu carregamento, da fase II.

Tabela 2. Médias do método Embrapa de avaliação de peletização (MEP) no caminhão logo após seu carregamento e durante a descarga da ração no silo de granja utilizando duas metodologias

\begin{tabular}{lc}
\multicolumn{1}{c}{ Tratamentos } & MEP (\%) \\
\hline Controle - Caminhão & $79,4 \mathrm{~A}$ \\
A - Abertura indicada para ração peletizada & $67,4 \mathrm{~B}$ \\
$\mathrm{~B}-$ Abertura indicada para ração farelada & $72,0 \mathrm{~B}$ \\
\hline CV\% & 8,8 \\
\hline
\end{tabular}

Médias seguidas de letras distintas diferem do tratamento controle pelo teste de Dunnet $(\mathrm{P} \leq 0,05)$.

De acordo com os resultados encontrados na Tab. 2, é possível verificar que a descarga do caminhão transportador influenciou na qualidade do pélete, com aumento de até $15 \%$ de finos na ração. Esse resultado está de acordo com aqueles encontrados na etapa anterior.
$\mathrm{Na}$ Tab. 3, são apresentados os resultados de MEP comparativos entre os dois métodos de descarga avaliados: descarga com menor abertura (apropriada para ração peletizada) e descarga com maior abertura (apropriada para ração farelada).

Tabela 3. Médias do método Embrapa de avaliação de peletização (MEP) em função do método de descarga utilizado

\begin{tabular}{lc}
\multicolumn{1}{c}{ Tratamentos } & MEP $(\%)$ \\
\hline A - Abertura indicada para ração peletizada & $67,4 \mathrm{~B}$ \\
B - Abertura indicada para ração farelada & $72,0 \mathrm{~A}$ \\
\hline
\end{tabular}

Médias seguidas de letras distintas diferem entre si pelo teste T-pareado $(\mathrm{P} \leq 0,05)$. 
A descarga de ração no silo da granja utilizando a menor abertura da caixa do caminhão, que seria a recomendada para ração peletizada pelo fabricante do veículo, piorou $(\mathrm{P} \leq 0,05)$ a qualidade física dos péletes comparada à descarga com maior abertura (piora de aproximadamente $6 \%$ ).

Conclui-se que a descarga da ração no silo da granja pelo caminhão é o ponto que mais influencia na qualidade dos péletes e que a descarga de ração peletizada deve ser realizada na maior abertura da caixa do caminhão. Além disso, o MEP se mostrou um método mais adequado do que o PDI para avaliar a integridade dos péletes que chegam até os frangos de corte.

Palavras-chave: frangos de corte, durabilidade, fábrica de rações, péletes

\begin{abstract}
The objective of this study was to evaluate the quality of pellets from the end of the pelletizer machine until the end of the line feed plate, using two methods of analysis: pellet durability index (PDI) and EMBRAPA pelletizing method (MEP). Furthermore, the effect of the discharging methods at the broiler farm on the physical quality of pellets using MEP as a method of analysis was evaluated. The first phase of the experiment was a randomized block with six treatments: A - pellets at the end of the pelletizer machine; $B$ - pellets inside the truck; $C$ - truck's discharging at the feed silo; $D$ - place inside the warehouse after the feed silo; $E$ - the middle of the feed plate line and $F$ - the end of the feed plate line. The experiment was carried out in seven replicates (blocks). The second phase of the experiment was a randomized block with two treatments: A - smaller discharge opening (for pellets feed); B - bigger discharge opening (for mashed feed). The experiment was performed with twelve replicates (blocks). The discharge of the pellets feed at broilers farm is the point that worsens the pellets quality. The discharge of pellets feed by the truck should be done with the bigger discharge opening. Moreover, MEP showed to be a better method than PDI to evaluate the integrity of the pellets for broiler chickens.
\end{abstract}

Keywords: broiler chickens, durability, feed mills, pellets

\section{AGRADECIMENTOS}

À Rivelli Alimentos, pelo apoio e dedicação dos funcionários a este trabalho; à Fapemig, por fornecer apoio para a publicação desta pesquisa.

\section{REFERÊNCIAS}

DOZIER, W.A. Pelet de calidad para obtener carne de ave más econômica. Alim. Balac. Anim., v.16, p.16-19, 2001.

KLEIN, A.A. Pontos críticos do controle de qualidade em fábricas de ração - Uma abordagem prática. In: I SIMPÓSIO INTERNACIONAL ACAV EMBRAPA SOBRE NUTRIÇÃO DE AVES, 1999, Concórdia. Anais. Disponível em: <http://docsagencia. cnptia.embrapa.br/suino/anais/anais56_klein.pdf >. Acessado em: 13/03/2012.

LÓPEZ, C.A.A.; BAIÃO, N.C. Efeitos do tamanho da partícula e da forma física da ração sobre o desempenho, rendimento de carcaça e peso dos órgãos digestivos de frangos de corte. Arq. Bras. Med. Vet. Zootec., v.56, p.214-221, 2004.
MCKINNEY, L.J.; TEETER, R.G. Predicting effective caloric value of nonnutritive factors: I. Pellet quality and II. Prediction of consequential formulation dead zones. Poult. Sci., v.83, p.1165-1174, 2004.

MEINERZ, C.; RIBEIRO, A.M.L.; PENZ JR., A.M. et al. Níveis de energia e peletização no desempenho e rendimento de carcaça de frangos de corte com oferta alimentar equalizada. Rev. Bras. Zootec., v.30, p.2026-2032, 2001.

NIR, I. Resposta de frangos de corte à estrutura alimentar: ingestão de alimentos e trato gastrointestinal. In: SIMPÓSIO INTERNACIONAL SOBRE NUTRIÇÃO DE AVES, 1998, Campinas. Anais... Campinas: CBNA, 1998. p.49-68.

SAMPAIO, I.B.M. Estatística aplicada à experimentação animal. 3.ed. Belo Horizonte: FEPMVZ, 2007, 265p.

SCHMIDT, A.; COLDEBELLA, A.; DE LIMA, G.J.M.M. Método Embrapa de avaliação de peletização. Comunicado Técnico, 2004. 
SHEIDELER, S.E. Poultry feeds: is pelleting cost effective? Feed Manag., v.46, p.21-26, 1995.

SKINNER-NOBLE，D.O.; MCKINNEY，L.J.; TEETER, R.G. Predicting effective caloric value of nonnutritive factors: III. Feed form affects broiler performance by modifying behavior patterns. Poult. Sci., v.84, p.403-411, 2005.
THOMAS, M.; VAN DER POEL, A.F.B. Physical quality of pelleted animal feed. 1 . Criteria for pellet quality. Anim. Feed Sci. Tech., v.61, p.89-112, 1996. 